\begin{tabular}{ccc}
\hline International Journal of Engineering \&Technology, $7(1.7)(2018) 118-120$ \\
SPC & Website: $w$ ww.sciencepubco.com/index.php/IJET \\
Research paper & Technology \\
\hline
\end{tabular}

\title{
Mobile based secured student online exam system
}

\author{
V.Lalitha ${ }^{1} *$, J. K. Periasamy ${ }^{1}$ \\ ${ }^{1}$ Department of Computer Science and Engineering, Sri Sairam Engineering College, Chennai, India \\ *Corresponding author E-mail: lalitha.cse@sairam.edu.in
}

\begin{abstract}
Mobile learning is a technology which uses wireless networks and mobile for learning. It facilitates learners to unite their experiences in learning in a collaborative and shared environment. Due to the widespread adoption and use of handheld devices, the mobile application technologies in enhancing learning activities have attracted noteworthy research interest. A Secure Exam Management System (SEMS) is designed for mobile environment and to simplify the exam management system. The teachers will define a bank of exam questions and link them to his/her subject through an appropriate interface (Subject's Question Bank Interface). The students can enter the exam system at the pre-defined date and time through the Exam Enrollment Interface. The students scan the QR code in the electronic device (Mobile/tablet) and then view an exam question in the same interface. As the school Wi-Fi network is connected to the students mobile or tablet, turning the network down during exams can avoid malpractice. Multifactor authentication can be adopted for stronger security.
\end{abstract}

Keywords: IOT based Android; Mobile-Learning; QR code; SEMS.

\section{Introduction}

Nowadays Mobile learning has experienced a large growth over the global industry market. Learning Management System, due to being essential tools of mobile learning, has been adopted by much organization to establish and provide access to online learning service. Many institution make use of bring your own device policy; in this case mobile can be used for learning and online examination purpose. Nowadays the Smartphone users have been increased, the latest survey says that the user will be nearly three times that of 2016. Interaction between user and social network have been increased after the emergence of mobile network [2-3]. Some of advantages of mobile learning are:

It is a student centered learning. It is a new alternative for information delivery. It enhances mutual learning. We have overcome the limitation such as there is no information delivery to the student. Teacher does not have interface to maintain student details. Automatic generation of question paper should be done. Malpractice of student can occur due to lack of security [5,7].

\section{Existing system}

In the existing system, students used to take online exams through computer. It will take more number of systems when there is huge number of students [1]. In some places due to limited number of computer they may take paper pen test or wait for the initial set of students to complete the exam. Most of the government exam has been taken through written exam. During the online exam, student may use hand-signals\|. There is no user friendly interface for both information delivery and maintaining the student details. Identify and authentication of security goals of model is insufficient [4] During the online examination students may use hand-signal for the exchange of information.

\section{Proposed system}

In proposed system, teacher will share their subject related full study material through mobile application. Enabling the teacher to define a exam question banks and to link them to his/her subject through an appropriate interface. Securely authenticating and enrolling students, using any of the well-known secure authentication mechanisms, into exams at the pre-defined date and time through the Exam Enrollment Interface. Creating exam instances by random distribution of exam questions and answers to the enrolled student's mobile/tablet devices to overcome the hand signals. Applying simple policies, such as turning down the network during exams if they attempt to use any alternative tabs in their mobile, the examination will get exit [6].

Feedback is taken after attending sessions about secured exam management system. There was enhanced \% of positive opinion of using it. The students felt that their grade would be better determined by means of using it. An additional authentication factor could increase the student confidence on the mobile based system. Secure exam management system make student and teacher comfortable using an interface.

\section{Methodology}

\subsection{Functional units}

Subject Allocation and Teacher login

Course and Question preparation

QR-code Generation

Student Exam process 


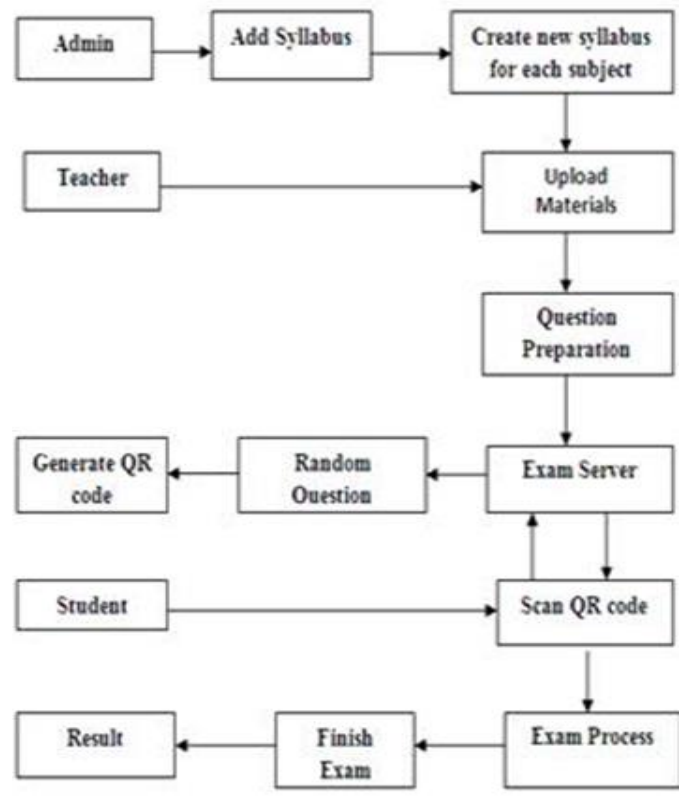

Fig. 1: Functional Unit.

\subsection{MVC Structure}

The technology of struts framework is used which is the open source framework that extinct java servlet API and employs a Model, View, and Controller.

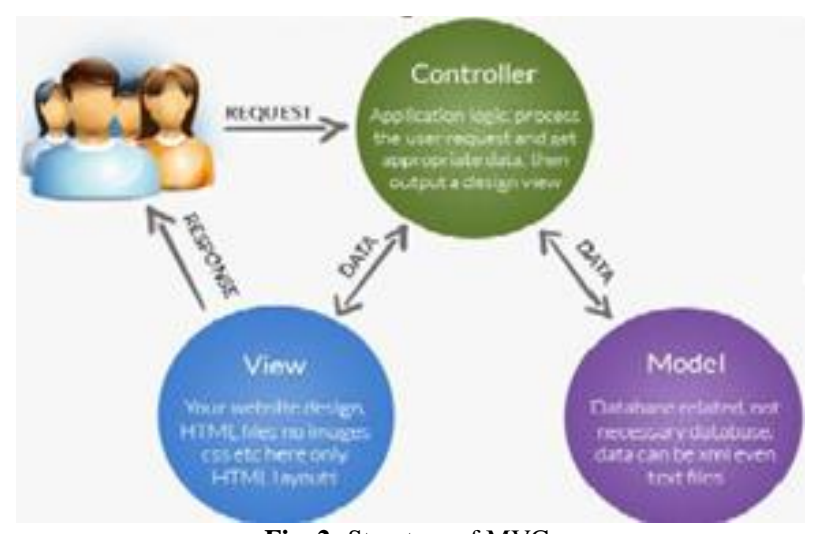

Fig. 2: Structure of MVC.

\subsection{MVC Controller}

MVC is a software design pattern for developing web based application. Model is the lowest level responsible for maintaining data. View is responsible for displaying a whole or a part of data. Controller is a software core which controls interaction between model and view.

\subsection{Algorithms}

Techniques that have been used are:

1) QR code generation techniques

2) Text to PDF conversion techniques

3) NLP techniques

4) Offline U-learning material preparation

5) U-learning material packager

6) Experiences and Outlook

\section{Performance evaluation}

\subsection{Subject allocation and teacher login}

In this module, admin login into QR U learning website. Then admin have to upload whole syllabus. The PDF contents of whole syllabus are parsed to text contents by copy paste operation. A new syllabus is created for that particular subject.

Each and every subject syllabus is created in similar ways. Admin can view the entire syllabus. Teacher should register the details like name, address, and subject specialization.

Admin can view all the teachers' details and allocate the syllabus to particular teacher according to their subject. While login in QR $\mathrm{U}$ learning website the syllabus allocated by the admin will be shown and can be downloaded in the teacher's main page. Teacher view the syllabus and understands the details.

\subsection{Course and question paper generation}

In this module the teacher will upload the core question papers for given subject, and then enabling the teacher to define a bank of exam questions and to link them to his/her subject through an appropriate interface (Subject's Question Bank Interface).

Each question may have a set of options. (let's say: A, B, C, D, and E).

\section{3. $Q R$ code generation}

In this module Exam server will generate the QR Code and include the exam questions. The question paper includes the exam date, time, duration and percentage of each level. The questions are not going to reach the students in the same order. The multichoices of each question, in case of objective questions, will be flipped randomly and delivered to each student. The Exam server generates the QR-code for each and every student.

\section{4. $Q R$ code scanning}

Student Exam Process

In this module students install the Exam Interface Application and then login into application.

The students scans the QR code in the electronic device (mobile) and then view the exam questions through the exam interface. Students will start the exam.

Exam interface will display the questions. After completed the exam student's click on finish to display the exam mark instantly in their application. Simultaneously students mark will be send to their log management.

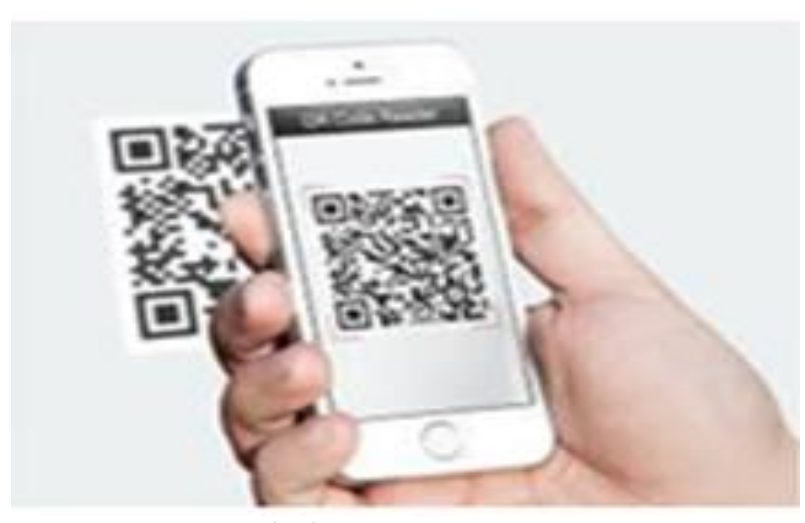

Fig. 3: QR Code Scanning.

\section{References}

[1] Mustafa Kaiiali, Armagan Ozkaya, Halis Altun, Hatem Haddad, and Marc Alier, "Designing a Secure Exam Management System (SEMS) for M-Learning Environments", IEEE transactions on learning technologies, vol. 9, no. 3, July-September 2016 https://doi.org/10.1109/TLT.2016.2524570.

[2] Kaiiali, M., Ozkaya, A., Altun, H., Haddad, H., \& Alier, M.,'Designing a secure exam management system (SEMS) for Mlearning environments", IEEE Transactions on Learning Technologies, pp. 258-27, $\quad$ September 2016. https://doi.org/10.1109/TLT.2016.2524570. 
[3] Abdul, W., Sengoku, Y. \& Mambo, M., "Toward constructing a secure online examination system", in proceedings of the 9th international conference on ubiquitous information management and communication. ACM, 2015.

[4] M.Yagci and M.Unal, "Designing and implementing an adaptive Online examination system", in Procedia-Social Behavioral Science, vol. 116, pp. 3079-3083, Feb. 2014.

[5] Y. Chen and W. He, "Security risks and protection in online learning-A survey", International Review of Research open distance learning for development., vol. 14, No. 5, pp. 108-127, Dec. 2013.

[6] Prerak Jain, Mani Kumdesh, Aarusi Goel, Harshita Malviya, "Design and implementation of e-exam using android platform, in International Journal Engineering Research \& Management Technology, Vol. 3, Issue 2, March 2016.

[7] Im Y. Jung and Heon Y. Yeom," Enhanced Security for Online Exams Using Group Cryptography", IEEE transactions on education, $\begin{array}{lllll}\text { vol. } & 52, & \text { no. } & \text { 3, }\end{array}$ https://doi.org/10.1109/TE.2008.928909. 